\title{
Estudo e Aplicação da Técnica eletrocinética para recuperação de solos contaminados com $\mathbf{C d}$
}

\author{
Natanael Júnior Soares Bento \\ Depto Engenharia de Agronegócios, EEIMVR, \\ $\mathrm{UFF}$ \\ 27255-125, Volta Redonda, RJ \\ E-mail: natanael.jsares@ig.com.br \\ Gustavo Benitez Alvarez \\ Depto de Ciências Exatas, EEIMVR, UFF \\ 27255-125, Volta Redonda, RJ \\ E-mail: benitez.gustavo@gmail.com
}

\author{
Fabiana Soares dos Santos \\ Depto Engenharia de Agronegócios, EEIMVR, \\ UFF \\ 27255-125, Volta Redonda, RJ \\ E-mail: fabianasoares@id.uff.br \\ Gilmar clemente da Silva \\ Depto de Ciências Exatas, EEIMVR, UFF \\ 27255-125, Volta Redonda, RJ \\ E-mail: gilmarcs@id.uff.br
}

\begin{abstract}
RESUMO
Sabe-se que, em concentrações adequadas, muitos metais pesados são essenciais para a vida e para os ecossistemas, como exemplo, temos os nutrientes que são necessários em quantidades adequadas para que a cultura possa crescer de forma adequada e ter uma produção rentável para o produtor, porém em quantidades excessivas podem causar danos para a mesma. Segundo Ho e El-Khaiary (2009) os principais danos à saúde e ao ambiente estão associados a metais pesados como chumbo, arsênio, cádmio e mercúrio. Ao contrário de muitos poluentes orgânicos, que degradam formando dióxido de carbono e água, metais pesados tendem a se acumular no meio ambiente, especialmente em lagos, estuários, ou sedimentos marinhos.

A remedição eletrocinética pode ser eficiente na extração de contaminantes em solos de textura argilosa, de baixa permeabilidade. Uma série de fatores determina o sentido e a extensão da migração do contaminante. Tais fatores incluem o tipo e as concentrações dos contaminantes, o tipo e a estrutura do solo e da química interfacial do sistema. A água ou alguma outra solução salina apropriada podem ser adicionadas ao sistema para melhorar a mobilidade dos contaminantes e aumentar a eficácia da tecnologia, em alguns casos coloca uma solução com um pH mais baixo para deixar os metais solúveis em solução. Os contaminantes aderidos aos eletrodos podem ser removidos por diversos métodos, inclusive galvanoplastia no eletrodo, precipitação no eletrodo, bombeamento de água perto do eletrodo, ou complexação com resinas de troca iônica (SHAMAS, 2009).

E percebendo a complexidade dessa nova técnica o nosso trabalho terá como objetivo o estudo das características químicas e físicas dos solos contaminados, a avaliação da dinâmica de metais pesados nos solos, o desenvolvimento e adequação da técnica de remediação eletrocinética nos laboratórios da UFF/EEIMVR e a sua modelagem através da diferenças finitas no ambiente computacional MATLAB ${ }^{\circledR}$ e a sua otimização através do algoritmo genético.

Para a implantação da parte experimental da técnica, foram coletadas amostras de solo de textura argilosa e média no município de Pinheiral - RJ. Os solos foram contaminados com Cloreto de Cádmio $\left(\mathrm{CdCl}_{2} \bullet \mathrm{H}_{2} \mathrm{O}\right)$ e as doses utilizadas foram calculadas com o objetivo de se obter tratamentos com concentração igual ao dobro, 10 vezes e 20 vezes o valor de investigação de Cd (3 mg kg $\left.{ }^{-1}\right)$ em solos de acordo com a Resolução do CONAMA 420 (2009).

Foi utilizado um reator eletroquímico e em suas extremidades foram posicionados eletrodos para a aplicação de um potencial elétrico de $16 \mathrm{~V}$ durante 72 horas. Através do campo gerado por este potencial foram criados gradientes de potencial, de concentração de íons metálicos e de $\mathrm{pH}$. Após a aplicação do potencial elétrico, os tratamentos foram retirados do reator, separandoos em diferentes regiões em relação ao catodo e ao anodo e em seguida foram feitas as suas análises e obtidos as concentrações desses metais para comparar com os resultados do modelo matemático que foi implementado no ambiente computacional MATLAB®.
\end{abstract}


O objetivo é a procura de soluções aproximadas das equações diferenciais parciais que modelam os fenômenos físicos do transporte de metais pesados em solos. Em geral, este é um problema difícil, e só raramente pode ser obtida uma solução analítica para equações diferenciais (LEVEQUE, 2007). Nosso modelo físico - matemático é baseado numa equação diferencial parcial linear de segunda ordem, que contem os termos difusivos, reativos, advecticos, uma fonte externa e os efeitos provenientes do potencial elétrico que é a eletroosmose e a eletromigração. O código computacional desenvolvido é implementando no ambiente MATLAB com as condições de contorno de Dirichlet e/ou Neumann, usando o método de Euler explicito, sendo usado as diferenças finitas de segunda ordem para as variáveis espaciais e a diferença finita avançada de primeira ordem para a derivada no tempo, contudo os códigos foram construídos considerando uma dimensão espacial (1D).

De acordo com os resultados obtidos na parte experimental, observou-se que a concentração de $\mathrm{Cd}$ na região próxima ao anodo foi menor que nas outras regiões, evidenciando que houve um deslocamento dos cátions metálicos provavelmente devido a redução do $\mathrm{pH}$ nessa região. Com o aumento do $\mathrm{pH}$ na região próxima ao catodo, o Cd provavelmente foi adsorvido ou precipitado, reduzindo a sua eficiência de remoção. Nos solos de textura média, as maiores concentrações de $\mathrm{Cd}$ foram encontradas na região do catodo e nos solos de textura argilosa na região mediana.

As simulações feitas para reproduzir os experimentos realizados anteriormente no laboratório, levaram em consideração os efeitos do potencial elétrico que é característico da técnica de remediação eletrocinética, é observado o transporte do contaminante no solo como era esperado e como foi visto nos experimentos realizados para os dois tipos de solo.

Palavras-chave: Remediação eletrocinética, metais pesados, fenômeno de transporte, Euler explicito e diferença finita.

\section{Referências}

[1] R. J. Leveque, "Finite difference methods for ordinary and partial differential equations : steady-state and time-dependent problems / Randall J. Leveque", Seattle, Washington, 2007.

[2] MATLAB®. Massachusetts: MathWorks, Inc, 2012.

[3] Y. Ho, M. I. El-Khaiary, Metal Research Trends in the Environmental Field. In: "Heavy Metals In The Environment". United States of America: CRC Press, 2009.

[4] CONAMA, RESOLUÇÃO N 420, DE 28 DE DEZEMBRO DE 2009.

[5] N. K. Shamas, Management and Removal of Heavy Metals from Contaminated. In: WANG, L.K et al. (Ed). In: "Soil Heavy Metals in the Environment". CRC Press. Boca Raton. 2009. 